\title{
Protecting the aged heart during cardiac surgery: The potential benefits of del Nido cardioplegia
}

\author{
Stacy B. O’Blenes, MD, ${ }^{\mathrm{a}, \mathrm{b}, \mathrm{c}}$ Camille Hancock Friesen, MD, ${ }^{\mathrm{a}, \mathrm{b}, \mathrm{d}}$ Ahmad Ali, ${ }^{\mathrm{c}}$ and Susan Howlett, $\mathrm{PhD}^{\mathrm{e}, \mathrm{f}}$
}

\begin{abstract}
Objective: Aged hearts are more vulnerable than mature hearts to reperfusion injury during cardiac surgery because of altered cardiomyocyte $\mathrm{Ca}^{2+}$ homeostasis. Inasmuch as immature cardiomyocytes have similar properties, a specialized cardioplegic solution (del Nido cardioplegia) designed to protect children's hearts may also be beneficial for elderly patients. Our objective was to evaluate the ability of del Nido cardioplegic solution, containing lidocaine and less $\mathrm{Ca}^{2+}$ than our standard cardioplegic solution, to protect aged cardiomyocytes during cardioplegic arrest and reperfusion.
\end{abstract}

Methods: We used our novel isolated cell model of cardioplegic arrest and reperfusion to compare the effect of del Nido cardioplegic solution with that of our standard cardioplegic solution on intracellular $\mathrm{Ca}^{2+}$ concentration, contractions, and membrane potential in cardiomyocytes from senescent rat hearts.

Results: The incidence of spontaneous contractions during cardioplegic arrest was lower with del Nido cardioplegia $(3 / 11$ vs $9 / 11$ cells; $P<.05)$ than with standard cardioplegia, and contractions could not be induced by field stimulation of cardiomyocytes arrested with del Nido cardioplegia $(0 / 11$ vs $9 / 11$ cells; $P<.05)$. Intracellular diastolic $\mathrm{Ca}^{2+}$ levels were lower during arrest with del Nido cardioplegia $(57.10 \pm 3.06$ vs $76.19 \pm 3.45 \mathrm{nmol} / \mathrm{L}$; $P<.05)$. During early reperfusion, a potentially injurious rapid recovery of intracellular $\mathrm{Ca}^{2+}$ associated with hypercontraction in cardiomyocytes arrested with standard cardioplegic solution was avoided in cells treated with del Nido cardioplegia $(81.42 \pm 2.99$ vs $103.15 \pm 4.25 \mathrm{nM} ; P<.05)$.

Conclusions: Del Nido cardioplegic solution has the potential to provide superior myocardial protection in senescent hearts by preventing electromechanical activity during cardioplegic arrest and $\mathrm{Ca}^{2+}$-induced hypercontraction during early reperfusion. (J Thorac Cardiovasc Surg 2011;141:762-70)

Elderly patients undergoing cardiac surgery have a higher risk of significant cardiac dysfunction and reduced survival than do younger adult patients. ${ }^{1,2}$ One reason is that older hearts are more susceptible to injury after periods of ische$\mathrm{mia}^{3,4}$ that occur during cardiac surgery. The mechanism for this intolerance to ischemia in senescent myocardium is related to changes in $\mathrm{Ca}^{2+}$ homeostasis resulting in intracellular $\mathrm{Ca}^{2+}$ levels during ischemia that are higher and increase at an accelerated rate. ${ }^{4-6}$ Myocardial injury after ischemia is mediated in part by $\mathrm{Ca}^{2+}$ overload-induced hypercontracture during early reperfusion. ${ }^{7,8}$ Limiting accumulation of intracellular $\mathrm{Ca}^{2+}$ during ischemia in aged hearts does improve recovery of ventricular function. ${ }^{6}$

Cardioplegic solutions protect myocardium against ischemia-reperfusion injury. They typically consist of blood

\footnotetext{
From the IWK Health Centre ${ }^{\mathrm{a}}$ and the Departments of Surgery, ${ }^{\mathrm{b}}$ Physiology and Biophysics, ${ }^{\mathrm{c}}$ Pathology, ${ }^{\mathrm{d}}$ Pharmacology, ${ }^{\mathrm{e}}$ and Medicine, Division of Geriatric Medicine, ${ }^{f}$ Dalhousie University, Halifax, Nova Scotia, Canada.

This work was supported by a Seed Grant from the Dalhousie University Department of Surgery.

Disclosures: Authors have nothing to disclose with regard to commercial support. Received for publication Jan 5, 2010; revisions received Feb 15, 2010; accepted for publication June 2, 2010; available ahead of print July 26, 2010

Address for reprints: Stacy B. O'Blenes, MD, IWK Children's Heart Centre, IWK Health Centre, 5850/5980 University Ave, PO Box 9700, Halifax, NS, Canada B3K 6R8 (E-mail: stacy.oblenes@iwk.nshealth.ca).

0022-5223/\$36.00

Copyright (C) 2011 by The American Association for Thoracic Surgery doi:10.1016/j.jtcvs.2010.06.004
}

mixed with a crystalloid solution containing a high concentration of $\mathrm{K}^{+}$and depolarize the cardiomyocyte cell membrane, thereby abolishing the generation and propagation of action potentials and the resulting contractions that are responsible for most of the metabolic activity of the heart. ${ }^{7,9}$ This slows the generation of intracellular acidosis as a result of anaerobic metabolism during ischemia and indirectly limits $\mathrm{Ca}^{2+}$ accumulation, ${ }^{7,10}$ thereby mitigating myocardial injury on reperfusion. However, standard cardioplegic solutions do not control intracellular $\mathrm{Ca}^{2+}$ levels as well in the aged myocardium, ${ }^{11}$ which correlates with increased myocardial injury on reperfusion in aged hearts. ${ }^{12}$

Immature hearts are also less tolerant to ischemia than is mature myocardium. ${ }^{13}$ They are poorly equipped to deal with postischemic $\mathrm{Ca}^{2+}$ overload ${ }^{14}$ and, therefore, are more sensitive to $\mathrm{Ca}^{2+}$-mediated injury during reperfusion. ${ }^{15}$ Strategies used in children to mitigate reperfusion injury include reducing $\mathrm{Ca}^{2+}$ in the cardioplegic solution and reperfusion with warm blood cardioplegic solution. ${ }^{15,16}$ Del Nido cardioplegia is a pediatric cardioplegic solution that has a low final $\mathrm{Ca}^{2+}$ content and contains an $\mathrm{Na}^{+}$channel blocker (lidocaine) that prevents $\mathrm{Na}^{+}$and, indirectly, $\mathrm{Ca}^{2+}$ accumulation in the cell during ischemia. ${ }^{17} \mathrm{We}^{18}$ have found that children undergoing heart surgery show evidence of less myocardial damage when del Nido cardioplegia is used instead of a standard cardioplegic solution. 
Given that immature and senescent hearts are both susceptible to myocardial injury owing to intracellular $\mathrm{Ca}^{2+}$ accumulation during ischemia, we investigated the possibility that a cardioplegic solution designed specifically to protect young myocardium (del Nido cardioplegia) may also have the potential to provide better protection for aged myocardium.

\section{MATERIALS AND METHODS Animals}

Experiments were performed in accordance with guidelines published by the Canadian Council on Animal Care (CCAC; Ottawa, Ontario: Vol 1, 2nd edition, 1993; Vol 2, 1984). Aged male Fisher 344 rats (24 months) were obtained from the National Institute on Aging (Baltimore, Md). Animals were maintained on a 12-hour light/dark cycle with free access to food and water.

\section{Cardiac Myocyte Isolation}

Ventricular myocytes were obtained by enzymatic dissociation as described previously. ${ }^{5}$ In brief, rats were heparinized (intraperitoneally, 3000 U/kg; Pharmaceutical Partners of Canada, Richmond, Ontario, Canada) and anesthetized with sodium pentobarbital (intraperitoneally, 160 $\mathrm{mg} / \mathrm{kg}$; CDMV, Saint-Hyacinthe, Quebec, Canada). Hearts were cannulated in situ through the aorta and perfused for 5 minutes $(18 \mathrm{~mL} / \mathrm{min}$, $37^{\circ} \mathrm{C}$, gassed with $\mathrm{O}_{2}$ ) with buffer solution containing ( $\left.\mathrm{mmol} / \mathrm{L}\right) 135.5$ $\mathrm{NaCl}, 4 \mathrm{KCl}, 10 \mathrm{HEPES}, 1.2 \mathrm{MgSO}_{4}, 1.2 \mathrm{KH}_{2} \mathrm{PO}_{4}, 12$ glucose, and 200 $\mu \mathrm{mol} / \mathrm{L} \mathrm{CaCl}_{2}(\mathrm{pH} 7.4)$ to clear the heart of blood. The above solution without $\mathrm{CaCl}_{2}$ was used to perfuse for an additional 5 minutes. This was followed by an enzymatic digestion for 20 minutes by perfusion with a buffer solution that contained $50 \mu \mathrm{mol} / \mathrm{L} \mathrm{CaCl}_{2}$ supplemented with protease dispase II (Roche Diagnostics, Laval, Quebec, Canada; $0.14 \mathrm{mg} / \mathrm{mL}$ ), collagenase type 2 (270 U/mg, Worthington, Lakewood, $\mathrm{NJ} ; 0.56 \mathrm{mg} / \mathrm{mL}$ ), and trypsin (Sigma-Aldrich, Oakville, Ontario, Canada; $0.02 \mathrm{mg} / \mathrm{mL}$ ). After perfusion with the enzyme solution, the ventricles were separated from the atria and minced in high potassium substrate-enriched buffer containing (mmol/L) $80 \mathrm{KOH}, 30 \mathrm{KCl}, 3 \mathrm{MgSO}_{4} .7 \mathrm{H}_{2} \mathrm{O}, 30 \mathrm{KH}_{2} \mathrm{PO}_{4}, 50 \mathrm{~L}$-glutamic acid, 20 taurine, 0.5 ethylene glycol tetraacetic acid, 10 HEPES, and 10 glucose ( $\mathrm{pH} 7.4$ with $\mathrm{KOH}$ ). The supernatant was then decanted and filtered through $225-\mu \mathrm{m}$ polyethylene mesh to remove large cellular debris. Only quiescent, rod-shaped cardiomyocytes with visible striations and no visible membrane damage were used experimentally. No more than 2 ventricular cardiomyocytes per heart were included in any data set.

\section{Cardioplegic Arrest Model}

Cardiomyocytes were incubated in a $0.75-\mathrm{mL}$ chamber mounted on the stage of an inverted microscope (Nikon ECLIPSE TE200; Nikon Canada, Mississauga, Ontario, Canada). The cells were then superfused with Tyrode solution containing $(\mathrm{mmol} / \mathrm{L}) 129 \mathrm{NaCl}, 20 \mathrm{NaHCO}_{3}, 0.9 \mathrm{NaH}_{2} \mathrm{PO}_{4}, 4 \mathrm{KCl}$, $0.5 \mathrm{MgSO}_{4}, 5.5$ glucose, and $1.8 \mathrm{CaCl}_{2}$ (pH 7.2; gassed with $95 \% \mathrm{O}_{2}$ and $5 \% \mathrm{CO}_{2}$ ). All experiments were conducted at $37^{\circ} \mathrm{C}$. Buffer solutions were heated to $37^{\circ} \mathrm{C}$ with a custom-made heat exchanger and a circulating water bath (Polystat Immersion Circulator; Cole Parmer Canada Inc, Anjou, Quebec, Canada). Superfusion with buffer was controlled by gravity to maintain a flow rate of $6 \mathrm{~mL} / \mathrm{min}$. The cells were equilibrated in oxygenated Tyrode solution for 10 to 20 minutes and then superfused with buffer solutions modified to approximate the final ionic concentrations of either del Nido or our standard adult cardioplegic solutions as delivered in the clinical setting (Table 1).

In the clinical setting, a stock crystalloid solution is mixed with the patient's blood in a ratio of 1:4 for the standard cardioplegia and a ratio of 4:1 for del Nido cardioplegia. Neither clinical solution contains added calcium, but because of the different proportions of blood in the final preparation, a significant difference in final calcium concentration between the 2 solutions exists. The cardioplegic solutions used for these in vitro studies contained no blood components. The cardioplegic solutions were bubbled with $90 \% \mathrm{~N}_{2}$ and $10 \% \mathrm{CO}_{2}$ and this gas was directed over the chamber to induce ischemia during cardioplegic arrest. After a 30-minute cardioplegic arrest period, cardiomyocytes were reperfused with oxygenated Tyrode solution for an additional 30 minutes. Myocytes were field stimulated at $4 \mathrm{~Hz}$ with 3-ms pulses delivered via a pair of platinum electrodes. Current stimulus and duration were controlled by Clampex 8.2 software (Molecular Devices, Sunnyvale, Calif) and an SIU-102 stimulus isolation unit (Warner Instruments, Hamden, Conn). Field stimulation was interrupted during cardioplegic arrest, except for brief periods at 12 and 22 minutes after the start of cardioplegia to check for cardiomyocyte excitability. Simultaneous recordings of contractions and intracellular calcium levels were made at regular intervals before, during, and after cardioplegic arrest as described below for a total of 65 minutes; responses remained stable for this length of time, as shown previously. ${ }^{5}$

\section{Measurement of Cardiomyocyte Contractions}

Unloaded cell shortening was measured with a video edge detector (model 105; Crescent Electronics, Sandy, Utah), coupled to a video camera on the microscope. Cell length and fluorescence were simultaneously recorded from each cell by splitting the microscope light with a dichroic cube. The video edge detector received red light, and remaining light was sent to the photomultiplier tube for fluorescence measurements (described below). Axoscope 8.2 (Molecular Devices) was used to record contractions. Ten-second recordings were taken every 5 minutes (with additional recordings at 12 and 22 minutes after induction of cardioplegic arrest and at 1 and 2 minutes after the beginning of reperfusion). Analog signals were converted to digital signals through a Digidata 1322A A/D board (Molecular Devices). Trains of contractions were averaged and measured with Clampfit 8.2 software (Molecular Devices). Contraction amplitude was defined as the difference between systolic and diastolic cell length.

\section{Measurement of Intracellular $\mathrm{Ca}^{2+}$}

Cells were loaded with the $\mathrm{Ca}^{2+}$-sensitive dye fura-2 AM $(5 \mu \mathrm{mol} / \mathrm{L}$, 15 minutes, room temperature; Invitrogen, Burlington, Ontario, Canada), and intracellular $\mathrm{Ca}^{2+}$ was measured by whole cell photometry (DeltaRAM, Photon Technology International, Evansville, Ind). The emission ratio at $510 \mathrm{~nm}$, during alternate excitation at $340 \mathrm{~nm}$ and $380 \mathrm{~nm}$, was used to determine intracellular $\mathrm{Ca}^{2+}$ concentrations. Background fluorescence values were determined at each excitation wavelength. These background values were subtracted from the recordings made at each wavelength during each experiment. Emission ratios were converted to intracellular $\mathrm{Ca}^{2+}$ concentrations with an in vitro calibration curve. Felix32 software (Photon Technology International) was used to record data. $\mathrm{Ca}^{2+}$ transient amplitudes were the difference between systolic and diastolic $\mathrm{Ca}^{2+} . \mathrm{Ca}^{2+}$ concentrations were recorded for approximately $10 \mathrm{sec}-$ onds. Trains of $\mathrm{Ca}^{2+}$ transients were averaged and peak responses were measured with Clampfit 8.2 software (Molecular Devices).

\section{Intracellular Recordings}

Some cardiomyocytes were impaled with glass microelectrodes $(30 \mathrm{~mol} /$ $\mathrm{L} \Omega$, filled with $2.7 \mathrm{~mol} / \mathrm{L} \mathrm{KCl}$ ) for simultaneous recording of membrane potential and unloaded cell shortening (as described earlier). Membrane potential was recorded with an Axoclamp 2B amplifier (Molecular Devices). Action potentials were initiated by injection of 3-ms current pulses (3-4 nA) at a frequency of $4 \mathrm{~Hz}$. Myocytes were stimulated in this manner under control conditions (before cardioplegia) and at various times during cardioplegic arrest with either del Nido or standard cardioplegia (Table 1). Resting membrane potential was measured with Clampfit 8.2 software.

\section{Statistical Analysis}

Data are presented as mean \pm SEM. Tests for statistical significance included 2-way analysis of variance with post hoc comparisons by 
TABLE 1. Composition and final ion concentration of cardioplegic solutions

\begin{tabular}{lcc}
\hline & $\begin{array}{c}\text { Standard } \\
\text { cardioplegia }\end{array}$ & $\begin{array}{c}\text { Pediatric (del Nido) } \\
\text { cardioplegia }\end{array}$ \\
\hline Composition (mmol/L) & 18.46 & \\
Na gluconate & - & 17.33 \\
Na acetate & 33.3 & 20.34 \\
$\mathrm{NaHCO}$ & & 13.79 \\
$\mathrm{NaCl}$ & 83.52 & 91.66 \\
$\mathrm{NaH}_{2} \mathrm{PO}_{4}$ & 0.72 & 0.18 \\
$\mathrm{MgSO}_{4}$ & 4.61 & 6.18 \\
$\mathrm{MgCl}_{2}$ & - & 1.13 \\
$\mathrm{KCl}$ & 18.42 & 24.3 \\
$\mathrm{CaCl}_{2}$ & 1.0 & 0.24 \\
$\mathrm{Glucose}$ & 4.4 & 1.1 \\
$\mathrm{Lidocaine}$ & - & 0.36 \\
$\mathrm{Mannitol}_{\mathrm{Ionic} \text { concentration (mmol/L) }}$ & 13.72 \\
$\mathrm{Na}^{+}$ & - & \\
$\mathrm{K}^{+}$ & 136 & 143.3 \\
$\mathrm{Mg}^{+}$ & 18.42 & 24.3 \\
$\mathrm{Ca}^{++}$ & 4.61 & 7.31 \\
\hline
\end{tabular}

Student-Newman-Keuls method only when the analysis of variance yielded a significant $P$ value, unpaired $t$ test, and Fisher's exact test where appropriate.

\section{RESULTS}

\section{Del Nido Cardioplegia Causes Larger Membrane Depolarization Than Standard Cardioplegia}

To evaluate the impact of standard and del Nido cardioplegia on membrane potential, we took intracellular recordings under control conditions (before cardioplegic arrest) and during cardioplegic arrest. There was a more pronounced resting membrane potential depolarization with del Nido cardioplegia than with standard cardioplegia ( $36.5 \pm 1.7$ vs $22.3 \pm 3.2 \mathrm{mV} ; P=.018 ; \mathrm{n}=3$ /group), but baseline values were not significantly different $(-77 \pm 3$ vs $-70 \pm 3 \mathrm{mV}$ ).

\section{Del Nido Cardioplegia Reduces Spontaneous and Inducible Activity During Arrest}

To determine the relative ability of our standard cardioplegia and del Nido cardioplegia to induce and maintain arrest in aged cardiomyocytes, we examined the recordings of $\mathrm{Ca}^{2+}$ transients and contractions made during the cardioplegic period. We observed spontaneous slow, low-amplitude $\mathrm{Ca}^{2+}$ transients associated with contractions in some cells despite the administration of either cardioplegic solution (Figure 1, A). However, a substantially lower proportion of cells showed spontaneous $\mathrm{Ca}^{2+}$ transients during cardioplegic arrest with del Nido cardioplegia when compared with those arrested with standard cardioplegia (Figure 1,B). This was associated with a corresponding reduction in the proportion of cardiomyocytes exhibiting spontaneous contractile activity (Figure 1, C). We also examined inducible activity during cardioplegic arrest by attempting to electrically stimulate the cells 12 and 22 minutes into the ischemic period (Figure 2, $A$ ). $\mathrm{Ca}^{2+}$ transients (Figure 2, B) and contractions (Figure 2, $C$ ) could be induced in approximately $80 \%$ of cells arrested with standard cardioplegia but not in any of the cells arrested with del Nido cardioplegia.

\section{Del Nido Cardioplegia Reduces Intracellular $\mathrm{Ca}^{2+}$ Levels During Arrest and Reperfusion}

The ability of our standard cardioplegia and del Nido cardioplegia to prevent intracellular $\mathrm{Ca}^{2+}$ accumulation during ischemic cardioplegic arrest and reperfusion was evaluated by comparing diastolic $\mathrm{Ca}^{2+}$ levels during these times (Figure 3). Both cardioplegic solutions prevented an accumulation of intracellular $\mathrm{Ca}^{2+}$ during ischemic cardioplegic arrest (Figure 3, A). However, intracellular diastolic $\mathrm{Ca}^{2+}$ levels were lower during arrest in cardiomyocytes treated with del Nido cardioplegia than in to those treated with standard cardioplegia (Figure 3,B). Perhaps most important, intracellular diastolic $\mathrm{Ca}^{2+}$ levels also remained lower during the critical early reperfusion period in cells arrested with del Nido cardioplegia than in those arrested with standard cardioplegia (Figure 3, C). These differences were apparent despite the fact that the reperfusion buffer was identical in each group (oxygenated Tyrode solution). We also examined recordings of the induced $\mathrm{Ca}^{2+}$ transients under control conditions (before cardioplegic arrest), during cardioplegia, and during reperfusion (Figure 4, A). Calcium transients could only be induced during the cardioplegic period in cells arrested with the standard cardioplegia (Figure 4, A, upper panel). However, $\mathrm{Ca}^{2+}$ transients returned in both groups on reperfusion. The magnitude of the $\mathrm{Ca}^{2+}$ transients was similar in both groups during reperfusion (Figure 4,B).

\section{Del Nido Cardioplegia Prevents Hypercontraction During Early Reperfusion}

We evaluated the contractile state of cardiomyocytes under control conditions (before cardioplegic arrest), during cardioplegia, and during reperfusion after cardioplegic arrest with either standard or del Nido cardioplegia by examining recordings of unloaded cell shortening (Figure 5, A). In cardiomyocytes arrested with standard cardioplegia, there was a rapid increase in contraction amplitude beyond baseline values during the critical early reperfusion period (Figure 5, B). However, in cardiomyocytes arrested with del Nido cardioplegia, contraction amplitude during early reperfusion was significantly lower and return to baseline was delayed (Figure 5, B). We also looked for evidence of hypercontracture during ischemia and reperfusion by examining diastolic cell length under control conditions (before cardioplegic arrest), during cardioplegia, and during reperfusion (Figure 5, $C$ ). There appeared to be a minor decrease in diastolic cell length during early reperfusion that was not 

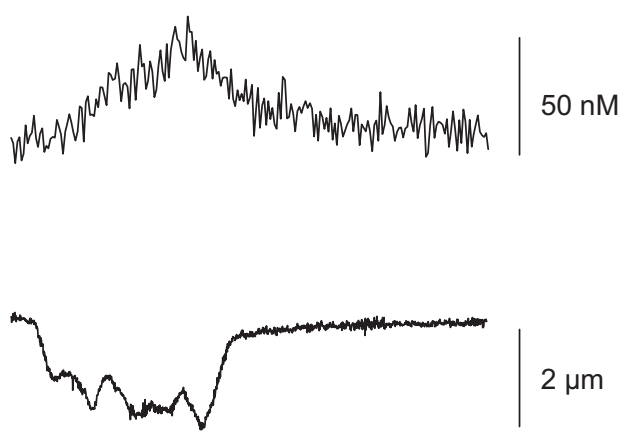

A

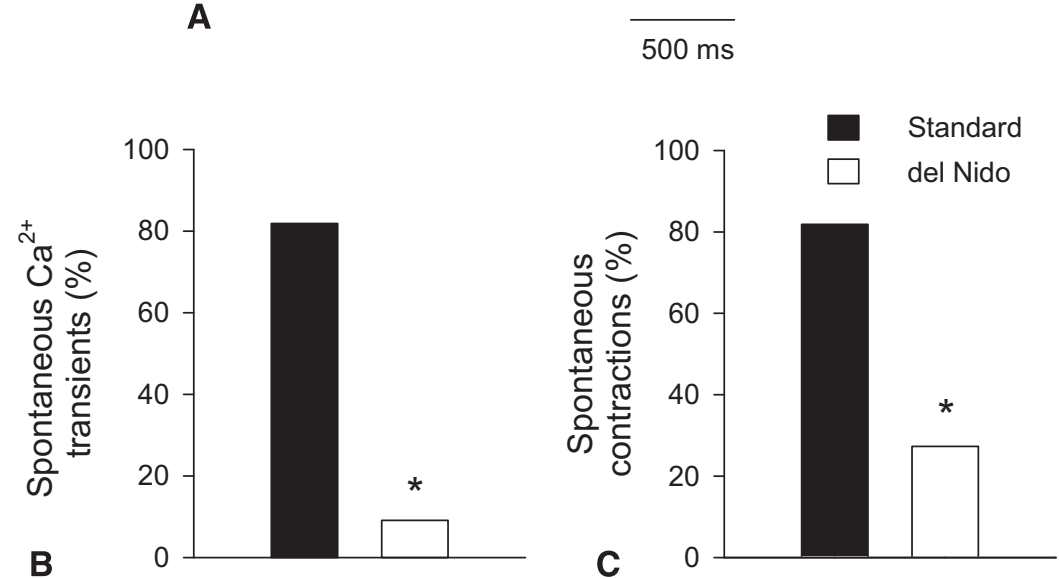

FIGURE 1. Analysis of spontaneous activity in cardiomyocytes during cardioplegic arrest. A, Representative tracings of spontaneous $\mathrm{Ca}^{2+}$ transients $($ upper panel) and cell length (lower panel) from cardiomyocytes during cardioplegic arrest. B, Bar graph representing the percentage of cardiomyoctes showing spontaneous $\mathrm{Ca}^{2+}$ transients during arrest with either standard or del Nido cardioplegia. C, Bar graph representing the percentage of cardiomyocytes showing spontaneous contractions with each cardioplegic solution. Total of 11 cells per group; $* P<.05$.

statistically significant and was not different between cells treated with standard or del Nido cardioplegia (Figure 5, C).

\section{DISCUSSION}

The unique characteristics of aged myocardium that make older hearts susceptible to $\mathrm{Ca}^{2+}$-mediated ischemiareperfusion-induced dysfunction after heart surgery suggest that a tailored myocardial preservation strategy could improve outcomes for this ever-expanding group of patients. Our results indicate that a cardioplegic solution designed to limit intracellular $\mathrm{Ca}^{2+}$ in immature myocardium may also be effective in senescent hearts.

We have demonstrated that del Nido cardioplegia is more effective than our standard cardioplegia at eliminating both spontaneous and inducible increases in intracellular $\mathrm{Ca}^{2+}$ and contractions in isolated aged cardiomyocytes during ischemic arrest. Eliminating this metabolic activity is expected to minimize the energy requirements, thereby delaying the development of intracellular acidosis as a result of anaerobic metabolism. Intracellular acidosis is a main driver of increased cytoplasmic $\mathrm{Ca}^{2+}$ levels during ischemia by promoting $\mathrm{Na}^{+}$influx through the $\mathrm{Na}^{+} / \mathrm{H}^{+}$exchanger and $\mathrm{Na}^{+} / \mathrm{HCO}_{3}$ symporter, which in turn causes $\mathrm{Ca}^{2+}$ influx through reverse mode $\mathrm{Na}^{+} / \mathrm{Ca}^{2+}$ exchange. ${ }^{8}$ Elevated intra- cellular $\mathrm{Ca}^{2+}$ is a major effecter of cardiomyocyte damage resulting from ischemia-reperfusion injury. ${ }^{7,8}$ It is therefore possible that more effective elimination of spontaneous and inducible activity seen at the cellular level with del Nido cardioplegia could translate into reduced ischemiareperfusion injury and improved heart function and therefore better outcomes after cardiac surgery in elderly patients.

Inducible activity is completely eliminated in cardiomyocytes arrested with del Nido cardioplegia. Two characteristics of del Nido cardioplegia possibly responsible for this observation are (1) higher $\mathrm{K}^{+}$concentrations that result in more pronounced membrane depolarization, which may be more effective at inactivating the voltage-dependent fast $\mathrm{Na}^{+}$channels responsible for action potential generation, and (2) the presence of lidocaine that blocks fast $\mathrm{Na}^{+}$channels, which may further prevent action potential generation. These 2 factors are synergistic because $\mathrm{Na}^{+}$-channel blockade by lidocaine is voltage sensitive and therefore enhanced in the setting of membrane depolarization. ${ }^{19}$

We observed spontaneous $\mathrm{Ca}^{2+}$ transients associated with contractions in cells from both cardioplegia groups. Spontaneous $\mathrm{Ca}^{2+}$ release from the sarcoplasmic reticulum does occur, particularly in the setting of $\mathrm{Ca}^{2+}$ overload. ${ }^{20}$ 

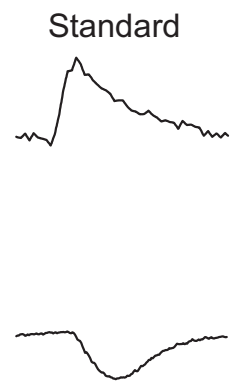

A

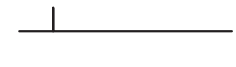

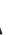

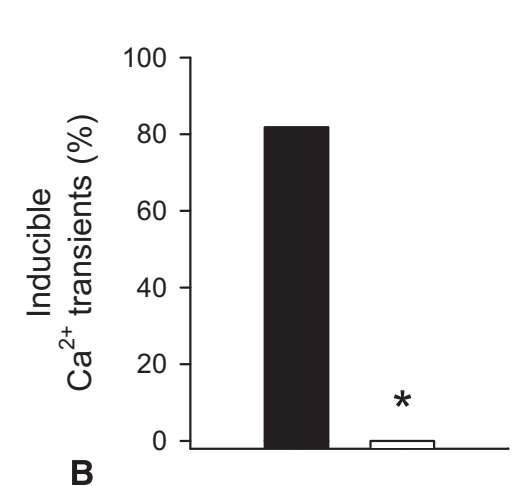

del Nido
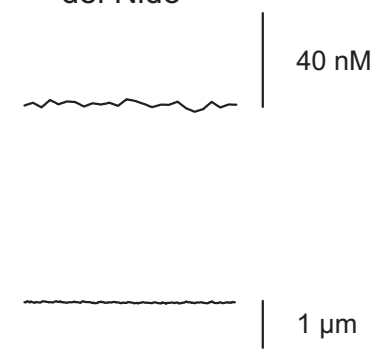

S
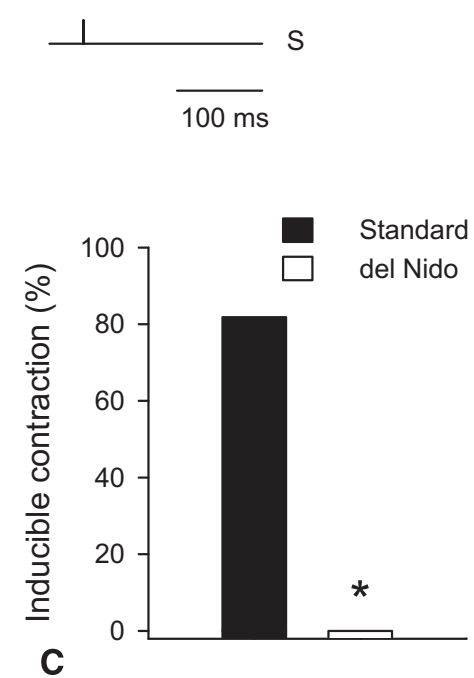

FIGURE 2. Analysis of inducible activity in cardiomyocytes field-stimulated during cardioplegic arrest. A, Representative tracings of Ca ${ }^{2+}$ transients $($ upper panels) and cell length (lower panels) from cardiomyocytes arrested with either standard or del Nido cardioplegia. Marker represents timing of the field stimulus. B, Bar graph representing the percentage of cardiomyocytes showing $\mathrm{Ca}^{2+}$ transients induced by field stimulation during arrest with each cardioplegic solution. C, Bar graph representing the percentage of cardiomyocytes showing contractions induced by field stimulation during arrest with each cardioplegic solution. Total of 11 cells per group; $* P<.05$.

The incidence of spontaneous $\mathrm{Ca}^{2+}$ transients and contractions is lower in cells treated with del Nido cardioplegia, which may be related to lower diastolic $\mathrm{Ca}^{2+}$ levels seen during ischemic arrest in this group of cells. Lower cytoplasmic $\mathrm{Ca}^{2+}$ concentrations could result in lower sarcoplasmic reticulum $\mathrm{Ca}^{2+}$ loading and therefore fewer spontaneous $\mathrm{Ca}^{2+}$ releases in cardiomyocytes arrested with del Nido cardioplegia.

In models of ischemia and reperfusion without cardioplegic arrest, a progressive increase in intracellular $\mathrm{Ca}^{2+}$ associated with contracture develops during the ischemic period. ${ }^{7,8}$ In contrast, we found low and gradually declining intracellular $\mathrm{Ca}^{2+}$ levels in cardiomyocytes arrested with cardioplegia during a 30-minute ischemic period. There are at least 3 factors likely responsible for this difference: (1) Eliminating electromechanical activity with cardioplegia minimizes anaerobic metabolism and the development of intracellular acidosis responsible for driving intracellular $\mathrm{Ca}^{2+}$ accumulation; (2) prolonged availability of adenosine triphosphate during ischemia as a result of the reduced metabolic rate may allow ongoing uptake of cytoplasmic
$\mathrm{Ca}^{2+}$ by the sarcoplasmic reticulum; (3) the cardioplegic solutions have low $\mathrm{Ca}^{2+}$ concentrations that would reduce the concentration gradient favoring movement of $\mathrm{Ca}^{2+}$ into the cell. Even though $\mathrm{Ca}^{2+}$ accumulation does not occur with either cardioplegic solution, intracellular $\mathrm{Ca}^{2+}$ concentrations are lowest with del Nido cardioplegia. This may be due to a lower $\mathrm{Ca}^{2+}$ concentration in del Nido cardioplegia than in the standard cardioplegia. Lidocaine present in del Nido cardioplegic solution may block the inward $\mathrm{Na}^{+}$"window" current that is active across the depolarized membrane, ${ }^{21,22}$ thereby preventing reverse mode $\mathrm{Na}+\mathrm{Ca}^{2+}$ exchange leading to $\mathrm{Ca}^{2+}$ influx.

Early reperfusion is a critical phase in the pathogenesis of ischemia-reperfusion injury. Excessive force generation during this period can lead to cell damage and/or death. ${ }^{8}$ This process typically manifests as $\mathrm{Ca}^{2+}$-induced hypercontracture resulting from restored availability of adenosine triphosphate to the contractile apparatus in the presence of elevated intracellular $\mathrm{Ca}^{2+}$ levels. ${ }^{8}$ We do not see true hypercontracture in our model because cardioplegic arrest prevents development of the elevated intracellular $\mathrm{Ca}^{2+}$ levels 

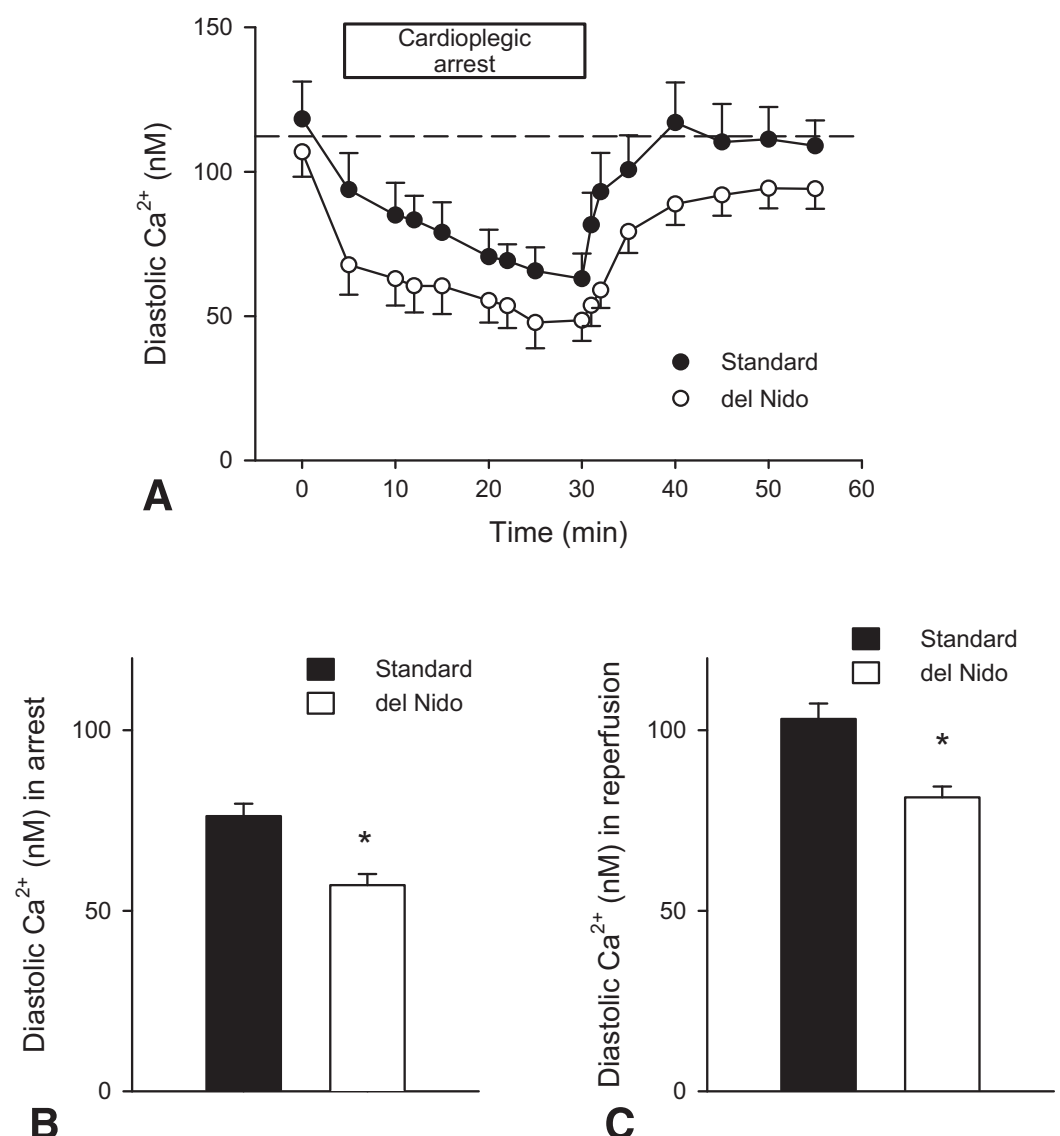

FIGURE 3. Analysis of diastolic $\mathrm{Ca}^{2+}$ levels during cardioplegic arrest and reperfusion. A, Graph showing diastolic $\mathrm{Ca}^{2+}$ levels measured in cardiomyocytes at several time points immediately before, during, and after 30 minutes of ischemic cardioplegic arrest with either standard or del Nido cardioplegic solution. Dashed line represents mean baseline value. B, Bar graph representing average diastolic $\mathrm{Ca}^{2+}$ levels during arrest with each cardioplegic solution. $\mathrm{C}$, Bar graph representing average diastolic $\mathrm{Ca}^{2+}$ levels during reperfusion after arrest with each cardioplegic solution. Data points and bars represent mean $\pm \mathrm{SEM} ; \mathrm{n}=11$ cells per group; $* P<.05$.

during ischemia that are responsible for this phenomenon. Despite this fact, we do see differences in the magnitude of contractions of our isolated cardiomyocytes during early reperfusion, depending on which cardioplegic solution was used. In cells treated with standard cardioplegia, we see rapid return of contraction amplitude beyond baseline values. In contrast, recovery of contractions to baseline values was more gradual after arrest with del Nido cardioplegia. We propose that even in the absence of significant hypercontracture, suppressing contractions during early reperfusion may still be beneficial in postischemic cardiomyocytes that appear to have a cytoskeleton that is fragile and unable to resist large contraction forces. ${ }^{8}$ The delay in the return of diastolic $\mathrm{Ca}^{2+}$ levels and contraction amplitude toward baseline values in aged cardiomyocytes arrested with del Nido cardioplegic solution may simply be related to the lower intracellular $\mathrm{Ca}^{2+}$ levels in these cells at the beginning of the ischemic period. However, residual lidocaine blockade of $\mathrm{Na}^{+}$channels during early reperfusion may also result in less $\mathrm{Ca}^{2+}$ influx or reduce contractility by shortening action potential duration independent of intracellular $\mathrm{Ca}^{2+}$ levels. ${ }^{23}$ The differences in contractions we see between the 2 cardioplegic solutions correlates with diastolic $\mathrm{Ca}^{2+}$ levels rather than the magnitude of the $\mathrm{Ca}^{2+}$ transient. This is consistent with our previous report that the degree of cell shortening increases with diastolic $\mathrm{Ca}^{2+}$ levels independent of a change in the $\mathrm{Ca}^{2+}$ transient. ${ }^{24}$

\section{Limitations}

This study focused on intracellular events during simulated cardioplegic arrest and reperfusion in an experimental system, the limitations of which must be considered when assessing the clinical implications of our results. We used senescent rat cardiomyocytes as a model of aged human myocardium. Although aged rodents are a practical model, information about the generalizability of conclusions from these models is limited. However, many age-associated changes in cardiac structure and function seen in humans are also observed in rodent models. ${ }^{3,4,25}$ In the clinical situation, the cardioplegic solutions we studied are usually 

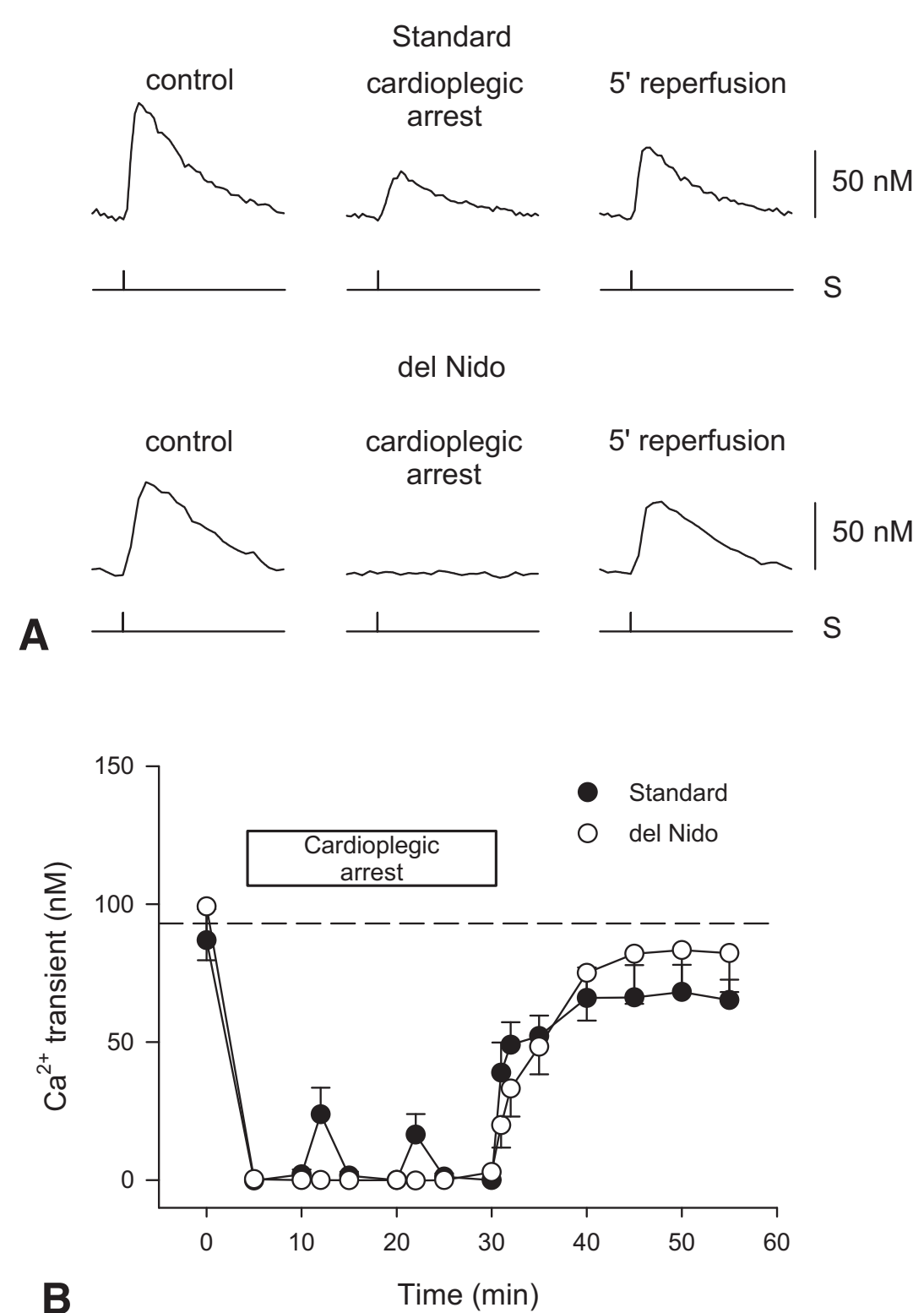

FIGURE 4. Analysis of $\mathrm{Ca}^{2+}$ transients during cardioplegic arrest and reperfusion. A, Representative tracings of $\mathrm{Ca}^{2+}$ transients recorded at baseline (control), during cardioplegic arrest with either standard (upper panel) or del Nido (lower panel) cardioplegia and after 5 minutes of reperfusion. Marker indicates timing of field stimulus. B, Graph showing $\mathrm{Ca}^{2+}$ transient values measured in cardiomyocytes at several time points immediately before, during, and after 30 minutes of ischemic cardioplegic arrest with either standard or del Nido cardioplegic solution. Dashed line represents the mean baseline value. Data points represent mean $\pm \mathrm{SEM} ; \mathrm{n}=11$ cells per group.

mixed with blood and delivered cold on an intermittent basis. It was not possible to include these conditions in our model. However, the cardioplegic solutions were formulated to mimic the ionic composition that would be found in the clinical solutions once mixed with blood. The solutions did not contain blood cells or proteins, which could have an impact on the results. Although it is true that cardioplegic solution is usually delivered cold, the presence of coronary artery disease and collateral flow can result in incomplete cooling of the myocardium and rewarming between doses. We propose that inadequately cooled myocardium may be susceptible to the type of spontaneous and inducible electromechanical activity that is prevented by del Nido cardioplegia. Although our cells were perfused continually during the experiment, the cardioplegic solutions were rendered hypoxic in an attempt to model the ischemic period that occurs between doses of cardioplegic solution clinically.

\section{CONCLUSIONS}

We have demonstrated that arrest with del Nido cardioplegia results in lower spontaneous and inducible activity 


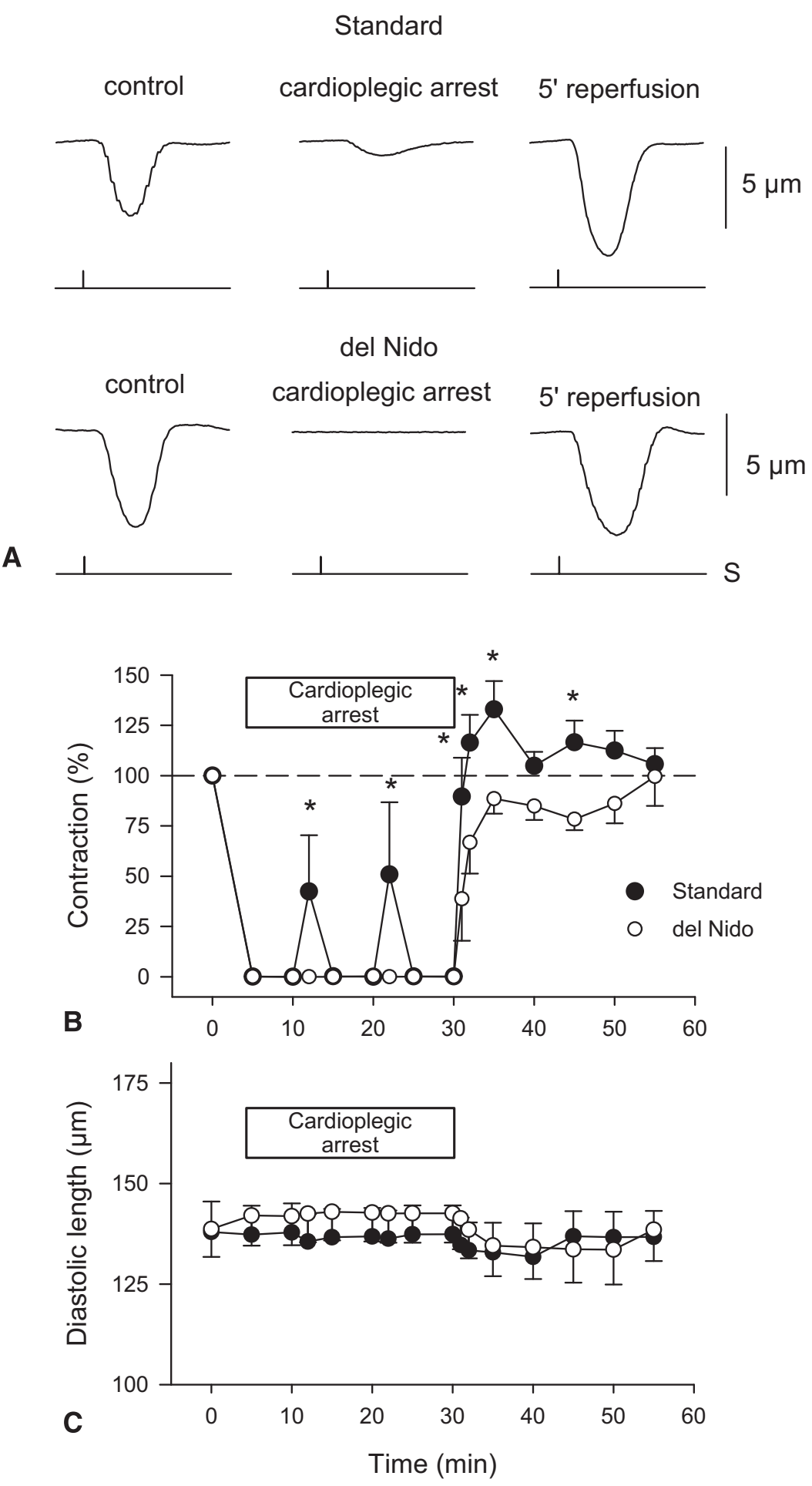

FIGURE 5. Analysis of contractions and diastolic cell length during cardioplegic arrest and reperfusion. A, Representative tracings of unloaded cell length at baseline (control), during cardioplegic arrest with either standard (upper panel) or del Nido (lower panel) cardioplegia, and after 5 minutes of reperfusion. Marker indicates timing of field stimulus. B, Graph showing contractions (magnitude of cell shortening) standardized to baseline value for each cardiomyocyte and measured at several time points before, during, and after 30 minutes of ischemic cardioplegic arrest with either standard or del Nido cardioplegic solution. Dashed line represents the mean baseline value. C, Graph showing diastolic cell length measured at several time points before, during, and after cardioplegic arrest. Data points represent mean $\pm \mathrm{SEM} ; \mathrm{n}=11$ cells per group. 
during the ischemic period, lower diastolic $\mathrm{Ca}^{2+}$ during ischemia and reperfusion, and gradual return of contraction amplitude during early reperfusion in aged cardiomyocytes when compared with standard cardioplegia. Isolated heart and whole animal preclinical studies will be required to determine whether the beneficial effects seen during ischemia and early reperfusion translate into improved cardiac function. Del Nido cardioplegia may have a place alongside other strategies, such as warm reperfusion, in a tailored approach to myocardial protection in the elderly.

We thank Peter Nicholl for his technical support.

\section{References}

1. Hirose H, Amano A, Yoshida S, Takahashi A, Nagano N, Kohmoto T. Coronary artery bypass grafting in the elderly. Chest. 2000;117:1262-70.

2. Shahian DM, O'Brien SM, Filardo G, Ferraris VA, Haan CK, Rich JB, et al. The Society of Thoracic Surgeons 2008 cardiac surgery risk models: part 1 -coronary artery bypass grafting surgery. Ann Thorac Surg. 2009;88(1 Suppl):S2-22.

3. Willems L, Zatta A, Holmgren K, Ashton KJ, Headrick JP. Age-related changes in ischemic tolerance in male and female mouse hearts. J Mol Cell Cardiol. 2005; 38:245-56.

4. Ataka K, Chen D, Levitsky S, Jimenez E, Feinberg H. Effect of aging on intracellular $\mathrm{Ca}^{2+}$, pHi, and contractility during ischemia and reperfusion. Circulation. 1992;86(5 Suppl):II371-6.

5. O'Brien JD, Ferguson JH, Howlett SE. Effects of ischemia and reperfusion on isolated ventricular myocytes from young adult and aged Fischer 344 rat hearts. Am J Physiol Heart Circ Physiol. 2008;294:H2174-83.

6. Tsukube T, McCully JD, Metz KR, Cook CU, Levitsky S. Amelioration of ischemic calcium overload correlates with high-energy phosphates in senescent myocardium. Am J Physiol. 1997;273(1 Pt 2):H418-25.

7. Steenbergen C, Murphy E, Watts JA, London RE. Correlation between cytosolic free calcium, contracture, ATP, and irreversible ischemic injury in perfused rat heart. Circ Res. 1990;66:135-46.

8. Piper HM, Garcia-Dorado D. Prime causes of rapid cardiomyocyte death during reperfusion. Ann Thorac Surg. 1999;68:1913-9.

9. Schaff HV, Dombroff R, Flaherty JT, Bulkley BH, Hutchins GM, Goldman RA, et al. Effect of potassium cardioplegia on myocardial ischemia and post arrest ventricular function. Circulation. 1978;58:240-9.

10. Flaherty JT, Weisfeldt ML, Hollis DP, Schaff HV, Gott VL, Jacobus WE. Mass spectrometry and phosphorus-31 nuclear magnetic resonance demonstrate addi- tive myocardial protection by potassium cardioplegia and hypothermia during global ischemia. Adv Myocardiol. 1980;2:487-99.

11. Tsukube T, McCully JD, Federman M, Krukenkamp IB, Levitsky S. Developmental differences in cytosolic calcium accumulation associated with surgically induced global ischemia: optimization of cardioplegic protection and mechanism of action. J Thorac Cardiovasc Surg. 1996;112:175-84.

12. Caldarone CA, Krukenkamp IB, Burns PG, Gaudette GR, Schulman J, Levitsky S. Blood cardioplegia in the senescent heart. J Thorac Cardiovasc Surg. 1995;109:269-74.

13. Wittnich C, Peniston C, Ianuzzo D, Abel JG, Salerno TA. Relative vulnerability of neonatal and adult hearts to ischemic injury. Circulation. 1987;76(5 Pt 2): V156-60.

14. Aoki M, Nomura F, Kawata H, Mayer JE Jr. Effect of calcium and preischemic hypothermia on recovery of myocardial function after cardioplegic ischemia in neonatal lambs. J Thorac Cardiovasc Surg. 1993;105:207-12.

15. Bolling K, Kronon M, Allen BS, Ramon S, Wang T, Hartz RS, et al. Myocardial protection in normal and hypoxically stressed neonatal hearts: the superiority of hypocalcemic versus normocalcemic blood cardioplegia. J Thorac Cardiovasc Surg. 1996;112:1193-200.

16. Allen BS, Barth MJ, Ilbawi MN. Pediatric myocardial protection: an overview. Semin Thorac Cardiovasc Surg. 2001;13:56-72.

17. van Emous JG, Nederhoff MG, Ruigrok TJ, van Echteld CJ. The role of the $\mathrm{Na}^{+}$ channel in the accumulation of intracellular $\mathrm{Na}^{+}$during myocardial ischemia: consequences for post-ischemic recovery. J Mol Cell Cardiol. 1997;29:85-96.

18. O'Brien JD, Howlett SE, Burton HJ, O'Blenes SB, Litz DS, Friesen CL. Pediatric cardioplegia strategy results in enhanced calcium metabolism and lower serum troponin T. Ann Thorac Surg. 2009;87:1517-23.

19. Bean BP, Cohen CJ, Tsien RW. Lidocaine block of cardiac sodium channels. J Gen Physiol. 1983;81:613-42.

20. Katra RP, Laurita KR. Cellular mechanism of calcium-mediated triggered activity in the heart. Circ Res. 2005;96:535-42.

21. Attwell D, Cohen I, Eisner D, Ohba M, Ojeda C. The steady state TTX-sensitive ("window") sodium current in cardiac Purkinje fibres. Pflugers Arch. 1979;379: $137-42$.

22. Chambers DJ. Mechanisms and alternative methods of achieving cardiac arrest. Ann Thorac Surg. 2003;75:S661-6.

23. Pankucsi C, Varro A, Nanasi PP. Three distinct components of the negative inotropic action of lidocaine in dog Purkinje fiber. Gen Pharmacol. 1996;27:69-71.

24. Shutt RH, Ferrier GR, Howlett SE. Increases in diastolic [Ca2 $\left.{ }^{\dagger}\right]$ can contribute to positive inotropy in guinea pig ventricular myocytes in the absence of changes in amplitudes of $\mathrm{Ca}_{2}^{+}$transients. Am J Physiol Heart Circ Physiol. 2006;291: H1623-34.

25. Lakatta EG. Arterial and cardiac aging: major shareholders in cardiovascular disease enterprises. Part III: cellular and molecular clues to heart and arterial aging. Circulation. 2003;107:490-7. 